\title{
Dietary Fat and Degenerative Vascular Diseases
}

G.

Pahlke

Prof. G. Pahlke, Bundesgesundheitsamt Berlin, Abteilung Ernährungsmedizin und Ernährungsphysiologie des Max-vonPettenkofer-Institutes, Berlin (FRG)

A Symposium entitled 'Nutritional Importance and Evaluation of Dietary Fats in the

Pathogenesis and Prevention of Degenerative Vascular Diseases' was held at the Federal Health Office in Berlin on January 30th and 31st, 1974. The following conclusions were unanimously adopted:

Coronary heart disease is a severe problem of preventive medicine and health care in the Federal Republic of Germany and in other industrialized nations. In the Federal Republic, deaths from ischemic heart disease amounted to 121,755 in 1973.

As a result of epidemiological, experimental, and clinical studies, a number of risk factors have become apparent, among which a raised serum cholesterol is prominent. The risk of coronary disease is relatively small for values of serum cholesterol below $220 \mathrm{mg} / 100 \mathrm{ml}$ serum. It increases considerably at concentrations of $260 \mathrm{mg} / 100 \mathrm{ml}$ and above. With the type of diet usually eaten in the Federal Republic of Germany, about two thirds of the male population have cholesterol values exceeding $220 \mathrm{mg} / 100 \mathrm{ml}$ serum.

Although the favourable effects of controlling the risk factors cannot be assessed quantitatively at present, the situation is grave enough to require that all reasonable measures to control them should now be taken.

It has been shown conclusively that the concentration of cholesterol in serum may be reduced by dietary measures. This could be achieved by a diet adjusted according to physical performance, i.e. in general a low-fat diet with a maximum of 20-25 \% of energy derived from fat. If the diet contains no more fat than this the relationship between fatty acids would not have the same importance as in the case of a high-fat diet.

Generally, however, such a diet does not correspond to the prevailing dietary habits in the Federal Republic of Germany and it would probably not be readily accepted. As an alternative measure, saturated fatty acids in the diet could be partially substituted by polyunsaturated fatty acids since this would also reduce the cholesterol level. At the same time, the reduction of the intake of dietary cholesterol to below $300 \mathrm{mg}$ /day should be attempted; this would Pahlke

114

hopefully lead to an additional reduction of serum cholesterol. Side effects of such dietary measures that would be of clinical relevance are not known.

The studies performed so far have shown that an adherence to such diets will reduce the incidence of coronary heart disease, above all in males. Measures taken at a young age will be more effective than those taken at an older age or even after the disease has become manifest. The importance of the concentration of triglycerides in the serum for the development of coronary heart disease has not been studied to the same degree as that of cholesterol, but it is likely that the association will be similar. It is known that hypertriglyceridemia is frequently 
associated with increased cholesterol values and/or diabetes and obesity. Levels of more than $150 \mathrm{mg}$ triglycerides in $100 \mathrm{ml}$ serum are to be considered as pathological and requiring treatment.

The following recommendations were unanimously adopted:

In view of the constant increase of coronary heart disease in the Federal Republic of Germany, regular and repeatedly performed medical examinations to recognize hyperlipidemia, and particularly hypercholesterolemia, are required to enable corresponding measures of preventive medicine to be taken. Persons with a high serum lipid level (cholesterol exceeding $220 \mathrm{mg}$ and triglyceride exceeding $150 \mathrm{mg} / 100 \mathrm{ml}$ serum) should be persuaded to change their eating habits. Principally, the objective should be a diet for the entire population from conventional foods which is fully adequate in respect of essential nutrients and energy, and limited in its fat content. A maximum intake of 20-25\% of energy from fat would lead to a reduction of cholesterol in serum both for prophylactic and therapeutic purposes.

Since experience has shown that most consumers are not prepared to reduce their excess fat consumption, there should at least be a partial substitution of saturated fatty acids in the diet by polyunsaturates. An ideal amount would be 10-15\% of total energy from polyunsaturated fatty acids.

On account of the known high intake of invisible fat from certain foods, particularly meat which consists mainly of saturated fatty acids, efforts should be made to promote foods (e.g. baked goods, meat products) with reduced fat content and increased proportion of polyunsaturates fatty acids in the fat. For the practical implementation of these dietary changes, all commercially handled foods will have to be examined for their fat. Appropriate foods should be generally available, economic in price and labelled in a way that is understood by consumers.

Research into the whole range of problems (including factors influencing the concentration of triglycerides in the serum) has to be intensified since prevention of and therapy for nutritional disorders have become particularly important in view of the continually increasing incidence of coronary heart disease.

Editorial

115

Participants

Helmut Rottka and Günter Pahlke (Chairmen), Bundesgesundheitsamt Berlin, Abteilung Ernährungsmedizin und Ernährungsphysiologie des Max-von-Pettenkofer-Institutes. Helmut Canzler, Medizinische Hochschule Hannover. Heinz Egge, Institut für Physiologische Chemie der Universität Bonn. Hermann Frahm, Bundesanstalt für Milchforschung, Kiel. Günter Fuchs, Institut für Medizinische Statistik und Dokumentation der Freien Universität Berlin. Hans Greggersen, Fachklinik für Innere Krankheiten der Landesversicherungsanstalt Hängebargshorst/Malente. Siegfried Heyden, Abteilung Präventivmedizin, Sanitätsdepartement des Kantons St. Gallen, Switzerland. Karl Irsigler, I., Medizinische Universitätsklinik Wien, Austria. Karl Jahnke, Medizinische Klinik der Ferdinand-Sauerbruch-Krankenanstalten Wuppertal- 